\title{
Diálogos da arqueologia sul-americana: Hermann von Ihering, o Museu Paulista e os museus argentinos no final do século XIX e início do XX
}

\author{
Lúcio Menezes Ferreira*
}

FERREIRA, L.M. Diálogos da arqueologia sul-americana: Hermann von Ihering, o Museu Paulista e os museus argentinos no final do século XIX e início do XX. Revista do Museu de Arqueologia e Etnologia, São Paulo, 19: 63-78, 2009.

Resumo: Este artigo mostra que as interpretações arqueológicas de Hermann von Ihering, o primeiro diretor do Museu Paulista, resultam em boa medida dos permanentes contatos que ele manteve com os museus argentinos e seus principais pesquisadores. Argumenta também que tais contatos permitiram a Ihering fundamentar uma política colonial.

Palavras-chave: Museu Paulista - Museus argentinos - Arqueologia SulAmericana - Política colonial.

1 ão há dúvidas sobre a excelência científica de Hermann von Ihering (1850-1930), o primeiro diretor do Museu Paulista. Estudou medicina, a partir de 1868, nas Universidades de Viena, Göettigen e Berlim. Doutorou-se, com tese sobre Paleontologia e Zoologia dos moluscos, pela Universidade de Göettigen, em 1876, e nesta mesma instituição, tão logo concluiu o doutorado, tornou-se professor assistente no Instituto de Zoologia. Em 1879, transferiu-se para a Universidade de Leipzig como Privatdozent de Zoologia. Chegou aos trópicos em 1880. Residiu inicialmente em São Leopoldo (RS), e deu seguimento às suas pesquisas, coletando, inclusive, várias espécies para o British Museum. Em 1883, nomearam-no para o posto de naturalista viajante do Museu Nacional. Desempenhou essa função residindo em várias cidades orladas pela Lagoa dos Patos, região onde amealhou coleções

(*) Universidade Federal de Pelotas. luciomenezes@uol.com.br paleontológicas, zoológicas e arqueológicas. Em 1894, entronizou-se na direção do Museu Paulista, cargo que ocupou por vinte e um anos.

Depois de sua demissão do Museu Paulista, em fins de 1915, convidaram-no para organizar um museu regional em Blumenau, Santa Catarina, encargo que não se concretizou por falta de recursos; esteve no Chile, trabalhou no Museu de La Plata e lecionou Zoologia na Universidade de Córdoba. ${ }^{1}$ Em 1924, voltou

(1) Os motivos da demissão de Ihering foram aventados na memória escrita pela neta do cientista, Maria von Ihering de Azevedo (2000). Segundo ela, seu avô sofrera perseguições xenofóbicas após a entrada do Brasil na I Guerra Mundial: sua origem alemã tê-lo-ia tornado persona non grata entre os cientistas brasileiros. Outras razões seriam malversação administrativa e nepotismo (pois o filho de Ihering, Rodolfo von Ihering, trabalhava no Museu como diretor-associado). Maria von Ihering ressalta que essas acusações foram injustas e caluniosas, e que seu avô recorreu aos fóruns para defender-se. Ana Maria de Alencar Alves (2001) mostra que a historiografia 
Diálogos da arqueologia sul-americana: Hermann von Ihering, o Museu Paulista e os museus argentinos no final do século XIX e início do XX.

Revista do Museu de Arqueologia e Etnologia, São Paulo, 19: 63-78, 2009.

para a Alemanha como professor honorário de Paleontologia da Universidade de Giessen, prosseguindo seus estudos com as coleções paleontológicas de Frankfurt. Sua notabilidade mundial conferiu-lhe diversas honrarias. Foi membro honorário de mais de trinta academias de ciências; seu nome batizou cinco gêneros e mais de 100 espécies. ${ }^{2}$ Celebrando o jubileu de ouro de seu doutorado, a revista Phoenix de Buenos Aires publicou sua biografia, rematada com uma lista, com mais de trezentos títulos, de suas publicações (cf. Phoenix, XIII, 1927: 7-60).

Seu renome internacional adveio principalmente a partir de 1907, quando ele, firmado em coleções de moluscos do sudeste sul-americano, versou sobre os antigos continentes Archelenis e Archinotis e desenvolveu a teoria das pontes continentais (Gesammelte Beiträge zur Geschichte der Neotropischen Region, 1907). O valor deste trabalho, que demonstrou a ligação paleontológica entre a África e a América do Sul, foi reconhecido por vários cientistas, dentre eles Alfred Wegener (1880-1930), o geólogo alemão proponente da teoria da deriva continental. ${ }^{3}$ Conquanto seja mais conhecido por suas prolíficas pesquisas zoológicas e paleontológicas, Ihering legou-nos também dezenas de textos arqueológicos e antropológicos. Suas pesquisas neste campo também o projetaram internacionalmente, sendo freqüentemente citadas em revistas estrangeiras, como na prestigiosa American Anthropologist (cf. p. ex: Chamberlain 1912; Haseman 1912; Saville 1913). Pode-se dizer, portanto, que a reputação mundial de Ihering, corolário de seus notáveis trabalhos paleontológicos e zoológicos, inscreveu-se também na esfera do seleto grupo dos americanistas.

sobre o Museu Paulista atribuiu a demissão de Ihering aos mesmos motivos arrolados por Maria von Ihering, mas que, contudo, não existem, nos arquivos da instituição, nenhum documento que os comprove.

(2) Para estes dados, cf. Obituaries, XLVII: 452-453, 1930

(3) Para se ter uma idéia da ampla aceitação da teoria

de Ihering, cf. algumas resenhas de época, publicadas no Bulletin of the American Geographical Society (Reviewed Works 1909), no Geographical Journal (Reviwed Works 1908) e na American Naturalist (Ortmann 1910).
Uma das marcas desta inscrição é a participação de Ihering no Congresso dos Americanistas de 1904, realizado em Stuttgart, onde ele apresentou um estudo sobre a distribuição geográfica dos muiraquitãs na América do Sul (Ihering 1904a). Contudo, já no XII Congresso dos Americanistas, realizado em Berlim, mencionaram-se as escavações de Ihering em sambaquis do Rio Grande do Sul, feitas quando ele era ainda naturalista-viajante do Museu Nacional. ${ }^{4}$ Em edições posteriores do Congresso dos Americanistas, os trabalhos arqueológicos e antropológicos de Ihering são também citados (Adam 1900: 317; Chamberlain 1906: 194; Bertoni 1924: 107; Heger 1924: 255). Ihering, pois, pode ser visto como americanista e, mais especificamente, como arqueólogo.

Frise-se que ele teve sua formação científica num país com consolidada tradição em curadoria de artefatos arqueológicos e em modernas técnicas de escavação. ${ }^{5}$ Assim, arqueólogos alemães influenciaram decisivamente, por exemplo, a Arqueologia britânica. Tome-se o caso de Sir William Matthew Flinders Petrie (1853-1942). Tido como um dos precursores dos métodos estratigráficos em escavação arqueológica (Gosden 1999: 55), ele cita largamente, em seu manual de Arqueologia, Methods and Aims in Archaeology (1904), arqueólogos alemães.

Ihering, ademais, iniciou sua carreira como assistente de Rudolf Carl Ludwig Virchow (18121902), renomado antropólogo físico; famoso, também, por envolver-se com Henrich Schliemann (1822-1890) nas pesquisas sobre Tróia e por suas participações no Congresso dos Americanistas (Virchow 1888a, 1888b). Assim, Ihering, já em seus primeiros trabalhos em laboratórios de museus, envolveu-se com Antropologia Física. Disciplina que, no século XIX, era indissociável da Arqueologia Pré-Histórica. Como afirma

(4) Cf. Congrés International des Américanistes. CompteRendu de la Septiéme Session, Berlim Déuxime Séance Ordinaire (1888: 99).

(5) Sobre a importância da Arqueologia alemã para o desenvolvimento da Arqueologia européia, e da britânica em particular, cf. Daniel 1950: 157 e Johnson 1993: 254-255. 
Roger Lewin (1997), os estudos antropométricos se impuseram a antropólogos físicos e a arqueólogos como um dos modos de se conhecer filiações históricas, especular sobre movimentos de imigração e postular esquemas evolutivos.

Mostrarei, nesse artigo, uma das facetas do Ihering americanista. O enfoque não incidirá sobre seu diálogo com as tradições brasileiras de pesquisa em Arqueologia, tema que já foi objeto de outros estudos (Funari 1999; Ferreira 2005a, 2007: 187-267). ${ }^{6}$ Abordarei um outro ângulo, mais continental e transnacional, das pesquisas arqueológicas de Ihering. Argumentarei que suas teses arqueológicas concretizaram-se em boa medida graças aos permanentes contatos que ele cultivou com os museus argentinos e seus principais diretores e cientistas: entre outros, Francisco P. Moreno (1852-1919), Florentino Ameghino (1853-1911), Samuel L. Quevedo (1835-1920) e Juan B. Ambrosetti (1865-1917). Tais contatos permitiram-lhe ampliar consideravelmente as coleções e a literatura arqueológica do Museu Paulista.

Enfatizarei, assim, que as teses arqueológicas de Ihering, bem como a política colonial que delas ele derivou, não seriam possíveis sem os intercâmbios institucionais alinhavados entre o Museu Paulista e os museus e pesquisadores argentinos. Trilharei parte de um caminho já percorrido por Margaret Lopes e Irina Podgorny (Lopes e Podgorny 2001, 2007; Lopes 2001). Em trabalhos sobre História das Ciências Naturais na América do Sul, elas mapearam uma fração significativa das relações institucionais e científicas entre Ihering e os cientistas argentinos. Assinalarei outros itens no mapa confeccio-

(6) Uma das evidências importantes sobre o diálogo de Ihering com as tradições locais de pesquisa é o modo como ele considerou efetivamente as pesquisas arqueológicas desenvolvidas, desde 1838, no Instituto Histórico e Geográfico Brasileiro (IHGB). Desde que assumiu a direção no Museu Paulista, Ihering procurou obter coleções completas da Revista do IHGB. Em ofício de 1894, ele solicitou diretamente ao IHGB exemplares da Revista, destacando a "raridade" de seus dados sobre a "natureza do Brasil e a vida dos aborígenes e à sua cultura antiga" (Ihering 1894a). Ainda sobre a Revista do IHGB, cf. Ihering 1897. Sobre as pesquisas arqueológicas do IHGB, cf. Ferreira 1999, 2003, 2005b. nado por Lopes e Podgorny, cartografando as dimensões propriamente arqueológicas dos diálogos travados entre Ihering e os argentinos. Pontuarei, para dizê-lo de outro modo, alguns dos diálogos da Arqueologia sul-americana em fins do século XIX e início do XX.

Mover-me-ei, aqui, pela confluência de duas perspectivas. A primeira aberta por recentes discussões em História da Arqueologia, segundo as quais os vínculos internacionais cosidos pelas instituições arqueológicas foram vitais para a formulação de teorias em Arqueologia PréHistórica (Kaeser 2000, 2001, 2002) e dos ideários políticos dos arqueólogos (Díaz-Andreu 2007). A segunda franqueada pelo conceito de mundialização da ciência. Para os historiadores latino-americanos da ciência, a cultura científica, ao internacionalizar-se no decorrer dos séculos XIX e XX, teceu um conjunto de representações historicamente situadas. Equivale a dizer: os liames entre ciência mundial e ciência "nacional" (ou nacionalizada) não levaram os cientistas a elidir tradições locais de pesquisa e tampouco a se isentar dos problemas políticos de seus lugares institucionais e geográficos de produção do conhecimento (Lafuente y Ortega 1992; Polanco 1990; Figueirôa 1998; Saldaña 1993; Lafuente 2000). Pelo contrário, ao dialogarem com a ciência internacional, os cientistas locais ativaram com suas pesquisas respostas para as questões políticas prementes de seus contextos. No caso de Ihering, uma das questões principais era a de assegurar, por meio de uma política colonial, a “civilização" e o "progresso" do oeste de São Paulo.

\section{Diásporas de Artefatos}

Ihering compartilhou com um modelo de interpretação arqueológica comum entre seus coetâneos: o difusionismo. Os debates difusionistas no americanismo remontam ao século XVIII (Frost 1993; Rueda 2003: 209-213; Sánchez 2004: 115-120); porém, seus maiores proponentes, nas primeiras décadas do século XX, foram Franz Boas (1858-1942) e Friedrich Ratzel (1844-1904) (Trigger 1990: 150-155; Harris 1968: 1993 e 620). Outro importante antropólogo que estabeleceu o difusionismo foi um 
Diálogos da arqueologia sul-americana: Hermann von Ihering, o Museu Paulista e os museus argentinos no final do século XIX e início do XX.

Revista do Museu de Arqueologia e Etnologia, São Paulo, 19: 63-78, 2009.

discípulo de Ratzel, o africanista Leo Frobenius (1873-1908). Frobenius seguiu o princípio geral dos difusionistas: não existem invenções culturais independentes; elas se fazem através dos intercâmbios entre grupos, em que os "mais civilizados e peritos" ensinam aos "mais primitivos e imperitos”. Frobenius, em 1900, forjou uma expressão para explicar os processos de difusão: em determinadas regiões, existiriam círculos culturais (Kulturkreise), circuitos por onde se deslocariam instituições sociais e artefatos (Schmidt 1942 [1913]: 2).

É possivel que Ihering tenha tido contato com as obras de Ratzer e Frobenius. Não as citou diretamente; todavia utilizou, coincidentemente, a expressão "círculos ondulatórios" para interpretar as relações culturais da Pré-História Sul-Americana. Fê-lo inicialmente no ensaio A Civilização Pré-Histórica do Brasil Meridional (Ihering 1895a), publicado no volume inaugural da Revista do Museu Paulista. Para Ihering, houve somente um núcleo de grande civilização na América do Sul: os Andes, a região em que se assentaram os Incas, o povo que, segundo ele, difundiu artefatos e elementos de uma "cultura civilizada” por toda a América do Sul. Em Arqueologia Comparativa do Brasil (Ihering 1904a), outro ensaio publicado na Revista do Museu Paulista, Ihering afirmou que quanto mais perto dos "círculos ondulatórios", ou seja, dos Incas, mais "civilizado" seria um povo indígena.

No Brasil, as diásporas dos artefatos incaicos, de acordo com Ihering, palmilharam duas rotas primordiais. A primeira seria a Amazônia. Mais especificamente, a Ilha de Marajó recebeu uma série de vasilhas cerâmicas. Tal difusão é que explicaria a refinada cerâmica marajoara. Mas este itinerário seria quase incidental, pois logo depois de acolherem os artefatos incaicos, os nativos da Ilha de Marajó, sempre segundo Ihering, engendraram uma indústria cerâmica local, com um novo estilo cultural. A segunda rota é que seria a principal, uma região arqueológica fundamental da PréHistória sul-americana: o Sul do Brasil. Os indígenas que se beneficiaram dos intercâmbios comerciais e culturais entre os Andes e o Sul do Brasil foram os Guaranis. Ihering descreveu os vestígios e artefatos que provariam a presença incaica entre os Guaranis: machados de cobre, adornos de ouro e prata, motivos pictográficos das cerâmicas e das pinturas rupestres, dentre outros (Ihering 1895a: 105-155).

Ihering traçou no mapa as irradiações dos "círculos ondulatórios" para o Sul do Brasil. Para ele, o datum zero, a coordenada primeira de onde partiram os artefatos de influência incaica para o Sul do Brasil foi a região subandina da Argentina. Mais precisamente, os artefatos foram remetidos pelos Calchaquis, a partir da província de Catamarca, no noroeste argentino. De acordo com Ihering, os Calchaquis, que viviam em Catamarca e também eram tributários dos Incas, mantiveram sólidos vínculos culturais com os Guaranis (Ihering 1895a: 126).

\section{Pontes antigas}

Para Ihering, portanto, pontes antigas ligaram Catamarca ao sul do Brasil (Ihering 1895a: 154-155). Isto se comprovaria nos materiais arqueológicos. Ihering conhecia diretamente os artefatos Calchaquis. Em 1904, Juan Ambrosetti e Francisco Moreno enviaram a Ihering uma coleção Calchaqui (Ihering 1904b, 16). Em 1910, os museus de La Plata e Nacional de Buenos Aires, bem como Samuel L. Quevedo, ofereceram outros materiais Calchaquis para o Museu Paulista (Hermann y Rodolfo von Ihering 1911: 2-3; 11). Por permuta, Ihering obteve ainda uma coleção Inca (Rodolfo von Ihering 1914: 10). Ihering pôde, pois, comparar os artefatos Calchaquis e Incas com a rica coleção Guarani arranjada no Museu Paulista. Inclusive utilizou - conforme vemos no Catálogo Arqueológico e Etnográfico produzido por ele no Museu Paulista - as classificações da "cultura Calchaqui" propostas por Ambrosetti. ${ }^{7}$ Baseando-se nestas

(7) Cf. Ihering 1914. Aqui, cabe uma observação técnica: no Fundo do Museu Paulista, este catálogo está classificado como sendo da lavra de Afonso d'Escragnolle Taunay (1876-1958), que viria a substituir Ihering no cargo de diretor do Museu Paulista a partir de 1917. Contudo, a redação do Catálogo começa em 1894 e prossegue até depois dos anos 1930. Como Taunay não trabalhava no Museu entre 1894 e 1917, é óbvio 
comparações, Ihering circunscreveu entre o noroeste argentino e o sul do Brasil um enclave arqueológico, uma identidade cultural entre os Calchaquis e os Guaranis, a qual estaria grafada nos artefatos de ambos os povos.

Ihering também fundamentou suas comparações na literatura arqueológica. Resenhando as obras de Juan Ambrosetti, Ihering enfatizou a necessidade de se cotejar os resultados das pesquisas arqueológicas dos países da América do Sul (Ihering 1900: 565). As pesquisas de Ambrosetti confirmavam, para Ihering, o que ele discutiu longamente em A Civilização Pré-Histórica do Brasil Meridional (Ihering: 1895a): a distribuição geográfica dos Guaranis e a rede de relações culturais entretecidas entre os Andes e o sul do Brasil. ${ }^{8}$ Ihering efetivamente dispunha de elementos comparativos. A hipótese acerca dos Andes como centro difusor das diásporas sul-americanas era sustentada pelos especialistas em Arqueologia do noroeste argentino: a exemplo do antropólogo holandês Hermann F. C. Ten Kate (1858-1931), curador da seção de Antropologia do Museu de La Plata, para quem a indústria metalúrgica dos Calchaquis inspirou-se nos Incas (Kate 1893: 348).

Ademais, Ihering, em seus textos do começo do século XX, sempre cita o americanista Eric Boman (1867-1924), antropólogo suíço que trabalhou, durante quase toda sua carreira, no Museu Nacional de História Natural de Buenos Aires. Boman escreveu uma vasta obra sobre Arqueologia, Antropologia e Lingüística do noroeste argentino, destacando-se, entre seus livros, Antiquités de la Region Andine de la Repúblique Argentine (1908). ${ }^{9}$ Em 1905, Boman afirmou que os Guaranis viveram no noroeste argentino, conforme atestavam os motivos figurativos das cerâmicas e urnas funerárias da região (Boman 1905). Ihering utilizou esta hipótese e procurou correlações e afinidades simbólicas entre as cerâmicas do noroeste argentino, do sul do Brasil, Paraguai e Bolívia, ou seja, delimitou todo um perímetro de contatos culturais e distribuição geográfica dos artefatos.

Com efeito, em vários de seus textos arqueológicos e antropológicos posteriores ao ensaio Civilização Pré-histórica do Brasil Meridional (1895a), Ihering trabalhou a hipótese sobre a ponte arqueológica entre o noroeste argentino e o sul do Brasil, acrescendo-lhe sempre novos dados e considerando detidamente a bibliografia arqueológica argentina (Ihering 1904a, 1904d, 1906, 1907a, 1907b).

\section{A origem do Homem Americano}

Mas Ihering nem sempre concordou com os trabalhos argentinos. Isto se clarifica em suas leituras da obra de Florentino Ameghino. ${ }^{10} \mathrm{Em}$ La Antigüedad del Hombre en el Plata (1918 [1880]), Ameghino argumentou que a evolução humana se deu na América do Sul durante o período terciário. A América do Sul seria um centro de evolução humana autônoma. Ainda que tenham cimentado o desenvolvimento da Arqueologia uruguaia e argentina, a tese central da obra de Ameghino foi contestada, inicialmente, por Hermann Burmeister (1807-1892), diretor do Museu Nacional de Buenos Aires

(10) Não obstante as discordâncias, Ihering e Ameghino eram grandes amigos. A amizade entre ambos pode ser apreciada no primoroso estudo de Lopes (2001). E transparece, inclusive, em suas publicações. Tome-se, por exemplo, um dos artigos de Ihering sobre os moluscos da Patagônia, publicado em Proceedings of the American Philosophical Society (1902a). Ihering batiza novas espécies com o nome de seu "amigo o Dr. Florentino Ameghino", em reconhecimento da qualidade de sua obra paleontológica e da "liberalidade" com que ele confiou-lhe coleções pessoais para estudos no Museu Paulista. 
Diálogos da arqueologia sul-americana: Hermann von Ihering, o Museu Paulista e os museus argentinos no final do século XIX e início do XX.

Revista do Museu de Arqueologia e Etnologia, São Paulo, 19: 63-78, 2009.

desde 1863 (Schávelzon 2004). ${ }^{11}$ Posteriormente, Ales Hrdlicka (1869-1943) e Paul Rivet (18761958) também refutaram a cronologia estabelecida por Ameghino (Hrdlicka 1917; Rueda 2003: 152-153).

Ihering valeu-se dos textos de Ameghino, particularmente das Noticias sobre Antigüedades Indias de la Banda Oriental (1877), para situar os contextos arqueológicos dos Calchaquis (Ihering 1895a: 61; 147; 151). Porém, também discordou da cronologia sobre a antigüidade do "homem americano" estipulada por Ameghino. Ihering posicionou-se neste debate mencionando suas escavações, feitas desde 1880, logo que chegou ao Brasil, nos sambaquis do Sul da costa brasileira. Fê-las, com efeito, no mesmo contexto de suas pesquisas paleontológicas e geológicas no sul do Brasil. As conclusões de Ihering e o questionamento da tese de Ameghino surgiram claramente em um artigo publicado em 1903, na Revista História, editada em Buenos Aires. Neste artigo, como nos indica o próprio título, Ihering sintetizou suas proposições principais sobre o El Hombre Prehistórico del Brasil (Ihering: 1903a).

Ihering começa narrando as transformações geológicas, botânicas e zoológicas que atingiram a costa Atlântica da América do Sul, desde o Rio Grande do Sul até a Patagônia. ${ }^{12}$ Procedeu, depois, a um exame das coleções de conchas e moluscos dos museus Paulista e de La Plata. Concluiu que as conchas dos depósitos marinhos da formação pampeana eram idênticas às espécies ainda vivas; por conseguinte, os restos

(11) Burmeister pode ser tido como um dos precursores das pesquisas paleontológicas e arqueológicas na Argentina. Assim o foi tido por seus próprios contemporâneos (Gutierrez 1875, 1877).

(12) Ihering, em diversos trabalhos realizados desde os anos 1880, concluiu que todo o Sul do Brasil, juntamente com a Argentina e os Estados do Rio de La Plata, configuraria, em termos paleontológicos e geológicos, um território singular. Isto porque os moluscos da costa da Argentina seriam similares aos do Sul do Brasil. Assim, todo o Sul do Brasil formaria com a Argentina uma identidade natural, a qual demarcaria uma diferença ontológica com as outras regiões brasileiras (Ihering: 1895b; 1897b; 1902b; 1969 [1885]). Estas pesquisas, acrescente-se, formaram a base para sua teoria da ligação paleontológica entre a África e a América do Sul. humanos desta formação, considerados terciários por Ameghino, seriam, na verdade, pós-terciários. O "hombre americano", portanto, não dataria, como os "primitivos" habitantes da Europa, do período terciário, mas sim do pós-terciário (Ihering 1903a: 162). Ihering iterou esta tese em outra oportunidade. Em 1909, programou uma série de quatro conferências a serem proferidas no Salão de Honra do Museu Paulista. ${ }^{13}$ Contudo, só viria a pronunciá-las na Alemanha, ainda em 1909, a convite do Museu Antropológico de Colônia, que recém-inaugurara suas instalações (Ihering 1911c: 513).

\section{Política colonial}

Penso que há ainda um outro vetor em que as experiências argentinas inspiraram Ihering: exatamente aquela que norteou sua política colonial. Para compreendê-la, é preciso deter-se na classificação antropológica que ele estipulou para os indígenas do Brasil. Ihering dividiu os grupos indígenas de maneira binária: de um lado, haveria os Guaranis do sul do Brasil, os que beberam das fontes Calchaquis e incaicas, os índios "semi-civilizados", beneficiários dos "círculos ondulatórios"; de outro, haveria os "índios primitivos", representados pela "raça” Jê. Estes, segundo as pesquisas Lingüísticas e em Antropologia Física de Ihering, seriam os herdeiros da "raça" mais "primitiva" da América, originária dos sambaquis do Brasil e hereditariamente ligada aos fósseis de Lagoa Santa, Minas Gerais, descobertos por Peter Wilhelm Lund (1801-1880) nos anos 1830. Para Ihering, esta divisão antropológica vigorou, no Brasil, desde a Pré-História (Ihering 1903a, 1903b, 1904d, 1907b, 1911a).

(13) Para a documentação referente a estas conferências, cf. Ihering 1909a; 1909b. Ihering dividiu-as do seguinte modo: " 1 História Geológica da América Meridional e origem de sua fauna; $2^{\circ}$ Cultura Primitiva, especialmente da Idade da Pedra; $3^{0}$ Ossos, fósseis do homem e de seus predecessores; $4^{\circ}$ Pré-História antiga do homem na Argentina e no Brasil" (Ihering: 1909a). Para comentários mais extensos destas conferências, cf. Ferreira 2007: 226 e segs. 
Ihering sustentou que a herança da "raça" primitiva do Brasil se transmitiu para dois grupos, então ainda vivos, da família Jê: os Botocudos e os Kainguangues, os quais, para ele, estorvavam, principalmente no oeste de São Paulo, o avanço do "progresso" e da "civilização". Neste contexto, havia em São Paulo uma guerra aberta contra estes índios. ${ }^{14} \mathrm{O}$ intuito era tomar-lhes as terras e expandir a economia agroexporatadora do café e das ferrovias. Ihering, assim, pontificou que, perante esses índios "primitivos e perigosos", que "assassinavam" colonos e engenheiros das ferrovias, a única solução seria exterminá-los, pois eles não representavam "qualquer elemento de trabalho e progresso" (Ihering 1907a: 215). ${ }^{15}$

Mas uma politica colonial não se faz somente com propostas de extermínio. Neste ponto, convém que eu defina o que entendo por política colonial. Para o caso da América Latina, pelo menos parte dos processos políticos pós-independência, notadamente aqueles que configuraram as relações entre os Estados nacionais e seus "outros culturais", pode ser descrita pelo conceito de colonialismo interno (Young 2001; Loomba 2000). O colonialismo interno é uma força política acionada a partir de dentro de uma fronteira nacional; ele ocorre quando uma elite utiliza a ciência ou o exército para imaginar geografias, classificar, governar e expropriar populações. Na América Latina, reiterou-se uma das características básicas da legitimação do

(14) Curt Nimuendaju (1883-1945), por exemplo, ao relatar seus trabalhos junto ao Serviço de Proteção aos Índios, disse em uma carta sobre a pacificação dos Kainguangues: "Haveria bem mais a relatar ao Senhor, porém o essencial de minhas observações é a luta racial asquerosa, que envergonha o interior paulista e que agora teve fim..." (Nimuendaju 1982 [1912]: 45). Grifos meus. (15) As relações entre as pesquisas arqueológicas e a proposta de extermínio de Ihering foram analisadas anteriormente (Funari 1994, 1998; Ferreira 2005a; 2007). Outros autores, como se sabe, descrevem o estado de guerra no interior paulista e demais Estados do Brasil, enfatizando a cerrada oposição à solução de extermínio de Ihering (Schwarcz 1989; Gagliardi 1989). Antonio Carlos de Souza Lima (1995) foi um dos primeiros a mostrar a lógica que subjazia à proposta de Ihering: promover a colonização de terras indígenas e a expansão do Estado Nacional. colonialismo pelas potências imperiais: a representação científica ou literária do "Outro" como sendo "primitivo", "degenerado", um ser inerte frente aos desdobramentos e transformações ritmadas pela evolução e pelo progresso (Goldie 1995: 236; Bsumek 2004: 321; Petersen y Rutherford 1995: 185).

Ihering, sem dúvida, promulgou um colonialismo interno. Além de representar cientificamente a maioria dos povos indígenas como "primitivos", elaborou também um plano completo de colonização. No texto intitulado A Questão dos Índios do Brasil (Ihering 1911b), ele precisou detalhadamente a maneira correta de governar os indígenas: com métodos de educação ocidental e ilhando-os em linhas de fortificação. Para Ihering, o trabalho de "civilização" dos indígenas deveria pautar-se pelas normas executadas nas colônias européias, onde os colonizadores, graças às pesquisas arqueológicas e antropológicas, conheciam a alteridade dos colonizados (Ihering 1911b: 4). Daí ele apelar para estratégias semelhantes àquelas que $\mathrm{o}$ antropólogo Bernard Cohn, estudioso das interações entre conhecimento e poder no Império Britânico, conceituou como modalidade enumerativa ("enumerative modality"): o uso de mapas, da demografia e da estatística para o governo dos nativos (Cohn 1996). Ihering enfatizou literalmente que o Museu Paulista, sob sua gestão, aparelhou expedições arqueológicas e etnográficas para compor mapas de distribuição geográfica e computar a demografia e a estatística dos índios. Mapas e números que ele anexou em A Questão dos Índios do Brasil para auxiliar as "tarefas administrativas" do Estado (Ihering 1911b: 138).

É verdade que Ihering tinha um modelo específico para conjugar as pesquisas arqueológicas e etnográficas com técnicas de governo: o Bureau of Ethnological Research da Smithsonian Institution, pertencente ao Museu Nacional dos Estados Unidos (Ihering: 1911b: 134). ${ }^{16}$ Ele

(16) Ihering, de fato, estabeleceu intercâmbios regulares com a Smithsonian Institution, um dos museus responsáveis por uma vasta circulação de idéias e coleções por todo o mundo (Goldstein 1994). Seus 
Diálogos da arqueologia sul-americana: Hermann von Ihering, o Museu Paulista e os museus argentinos no final do século XIX e início do XX.

Revista do Museu de Arqueologia e Etnologia, São Paulo, 19: 63-78, 2009.

inspirou-se precisamente na instituição que Curtis Hinsley analisou como sendo encarregada de promover uma "ciência de governo" dos índios ("government science") (Hinsley 1981, 81-190). Mas o horizonte das pesquisas e estratégias políticas argentinas também se apresentou às referências de Ihering. Segundo ele, a Argentina teve dificuldades semelhantes às do Brasil para povoar seu território; contudo, construindo, como ele queria para o Brasil, linhas de fortificação nas cercanias dos rios Negro e Chaco, a Argentina "abrigou ferozmente a civilização" (Ihering 1911b: 113). ${ }^{17}$

É possível que Ihering tenha aprovado a expedição argentina chamada de Conquista do Deserto (quase um homônimo da Conquista do Oeste dos Estados Unidos). Ocorrida entre 1879 e 1881, esta expedição militar, que rastreou as regiões entre os Pampas e a Patagônia, contou com cientistas, os quais coletaram artefatos e crânios. Francisco Moreno, que integrou a expedição, parecia cultivar obsessão patológica por crânios e medidas antropométricas (Stagnaro 1993; Podgorny 1997). ${ }^{18}$ Um museu foi especialmente erigido para armazenar e exibir estes materiais: o Museu de La Plata, cujo primeiro diretor foi o próprio Francisco Moreno (Politis 1995: 199; Podgorny e Politis 1992; Podgorny 2000). Ademais, a Conquista do Deserto seguiu

contatos mais assíduos foram com o secretário geral da Smithsonian, George Brown Goode (1850-1896), um inovador na teoria museológica moderna (Kohlstedt 1988). Para os contatos entre ambos, cf., por exemplo, as cartas de Brown Goode 1894, 1896, nas quais ele propõe a permuta de coleções arqueológicas e etnográficas. Ihering também permutou com a Smithsonian coleções zoológicas e, principalmente, classificou, para os cientistas da instituição, espécies zoológicas (Carta da Smithsonian Institution 1896a, 1896b; Langley 1897).

(17) Guillermo Alfredo Terrera (1974: 25-32) descreve minuciosamente as linhas de fortificações que vigiavam todo o norte da Argentina das incursões dos indigenas do Chaco Austral e outras regiões. As linhas de fortificações são mencionadas também por Antonio Alberto Guerrino (1984).

(18) Em texto sobre a distribuição geográfica e classificação lingüística dos grupos indígenas da Argentina, Moreno menciona sua participação na Conquista do Deserto (Moreno 1901: 574). os procedimentos clássicos das políticas coloniais: depois de exterminar os índios e pilhar-lhes os artefatos, passou-se ao butim; as terras indígenas foram repartidas entre os membros do exército, e posteriormente loteadas e vendidas para colonos estrangeiros (Haber 1994: 32).

A guerra como gabarito de obtenção de coleções arqueológicas e etnográficas era admitida por Ihering. ${ }^{19}$ Em 1906, o Museu Paulista recebeu mais de duzentos artefatos Kainguangues. Foram enviados pela Comissão Geológica e Geográfica de São Paulo, cujos membros realizaram, entre 1905 e 1906, expedições pelos Rios Feio, Peixe e Paranapanema, exatamente na região em que viviam os Kainguangues. Ihering definiu esta coleção como rara e repleta de novos elementos antropológicos. Com ela, Ihering fundamentou um de seus ensaios, especificamente aquele onde ele propugnou pelo extermínio dos Kainguangues: A Antropologia do Estado de São Paulo (Ihering 1907a), ensaio escrito originalmente em inglês, para ser apresentado na Exposição de Saint Louis de 1904.

Neste ensaio, podemos ler a narrativa sobre a coleta dos artefatos. Os Kainguangues, segundo Ihering, seriam praticamente desconhecidos do ponto de vista antropológico, pois eram refratários a "qualquer relação amistosa com a população brasileira" (Ihering 1907a: 211). Inclusive, cometeram "assaltos" contra a Comissão Geográfica e Geológica (Ihering 1907a: 211). A Comissão, não obstante, rechaçou o ataque. Em 24 de setembro de 1906, lançou-se "imediatamente em perseguição dos selvagens, batendo matas e descobrindo

(19) A guerra como estratégia para amealhar coleções foi parte substancial das pesquisas arqueológicas e etnográficas em todo o mundo, principalmente aquelas deflagradas pelos países colonialistas (Cohn 1996; Paczensky 1985). Não deixa de ser sintomático que o tenha sido também nos Estados Unidos, em cuja capital construiu-se a Smithsonian Institution, a instituição que inspirou Ihering a pensar sua política colonial conjugada com pesquisas arqueológicas e etnográficas. Randall MacGuirre conta-nos que, conforme o exército dos Estados Unidos repelia os indigenas para o oeste e os confinava nas reservas, antropólogos e arqueólogos saqueavam as sepultaras recentes dos nativos e faziam coletas de artefatos no campo de batalha (MacGuirre 1992: 53-59). 
por esta ocasião a vivenda dos mesmos Kainguangues" (Ihering: 1907a: 212). Com esta ofensiva, a Comissão colheu para o Museu Paulista, além de duzentos artefatos, uma série de dados que, para Ihering, "mudaram a situação precária quanto ao conhecimento dos Kainguangues de São Paulo" (Ihering 1907a: 213).

Os relatórios da Comissão Geográfica e Geológica são indubitáveis quanto ao caráter simultaneamente científico e militar da expedição para o oeste de São Paulo. Os membros da Comissão partiram para a região com modernas armas de repetição, dispostos a "desbaratar" os Kainguangues:

"Em 27 viajamos sem maior novidade, quando as 9:40 h, por um dos práticos, fomos avisados da proximidade dos indios; e, de fato, encontramos pouco adiante, em uma curva do Rio, um numeroso grupo de indios, o qual foi desbaratado por nós, tendo eles na fuga deixado 34 flechas, 2 arcos, 1 vara de pescar e outros pequenos objetos. É possivel que tenha havido perda por parte deles; pois vimos grande quantidade de sangue no sitio" (Lima Júnior 1906: 11-12).

Ihering, no relatório do Museu Paulista para os anos 1906/1909, registrou a compra de um armário novo para expor o "material raro que o Museu recebeu da Comissão Geográfica e Geológica do Estado, que o coligiu em suas explorações do interior desconhecido, no Oeste de São Paulo" (Hermann e Rodolfo von Ihering 1911: 6). Certamente Ihering não mascarou com o armário novo o modo como se logrou a coleção Kainguangue: artefatos granjeados por meio de uma situação colonial; a cultura material nativa recolhida pelo saque.

\section{As duas margens do diálogo}

Em 1910, no Congresso Internacional dos Americanistas, sediado em Buenos Aires, Ihering pronunciou novamente sua tese sobre Etnografia e Arqueologia do Sul do Brasil (Ihering 1910). ${ }^{20}$

(20) Para uma descrição detalhada deste Congresso e seu papel na institucionalização da Arqueologia argentina, cf. Podgorny 2004.
Esboçou os "círculos ondulatórios" que ligaram a Pré-História do noroeste argentino ao Sul do Brasil; pontuou suas divergências com Ameghino e discorreu seus argumentos sobre a procedência pós-terciária dos indígenas sulamericanos (Ihering 1910: 250-260). Finalmente, dissertou sobre sua política colonial. Destacou as expedições arqueológicas e etnográficas que organizou e as coleções que reuniu no Museu Paulista; apresentou ao público os números demográficos que computou e os mapas de distribuição geográfica dos indígenas que confeccionou. Em suma, mostrou que as pesquisas arqueológicas e etnográficas poderiam subsidiar uma ciência de governo das populações indígenas (Ihering 1910: 261-262). Depois da apresentação, Ihering e Samuel L. Quevedo debateram. Mas não houve maiores discrepâncias. Quevedo apenas pediu a Ihering alguns esclarecimentos sobre a Etnografia do Alto Paraná (Ihering 1910: 263-264).

Como argumentei ao longo deste artigo, Ihering, para firmar suas teses arqueológicas e antropológicas, sempre recorreu às pesquisas e coleções argentinas. É possível identificar também que as experiências políticas argentinas, especialmente a Conquista do Deserto, serviram de inspiração para Ihering elaborar sua política colonial. A julgar pelo debate no Congresso dos Americanistas de 1910, pode admitir-se que, por seu turno, os cientistas argentinos não destoavam da política colonial de Ihering. Do mesmo modo, não discordavam substancialmente das teses arqueológicas e antropológicas do diretor do Museu Paulista. A relativa concórdia entre Ihering e os argentinos é facilmente aquilatada, aliás, não só no Congresso dos Americanistas de 1910. Se é verdade que Ihering utilizou as pesquisas argentinas e inclusive publicou em Revistas de Buenos Aires (como na Revista Historia), os cientistas "del otro lado del Plata" também se valeram dos trabalhos de Ihering.

É o caso, por exemplo, de Luís de María Torres (1878-1937). Em Los Habitantes Primitivos del Delta del Paraná (1911), Torres descreve as extensas escavações que concretizou no baixo Rio Paraná e Uruguai. Analisa a cultura materi- 
Diálogos da arqueologia sul-americana: Hermann von Ihering, o Museu Paulista e os museus argentinos no final do século XIX e início do XX.

Revista do Museu de Arqueologia e Etnologia, São Paulo, 19: 63-78, 2009.

al e os esqueletos humanos descobertos..$^{21}$ Torres se amparou no artigo Arqueologia Comparativa do Brasil (Ihering 1904c) para fundamentar classificações lingüísticas dos grupos indígenas Jê e das indústrias cerâmicas dos Tupis (Torres 1911: 402, 405, 411, 424, 513, 558, 559). Usou também El Hombre Prehistórico del Brasil (1903a). Segundo Torres, os argumentos de Ihering sobre os sambaquis e acerca da ascendência pósterciária dos nativos sul-americanos estavam corretos (Torres 1911: 518-521). Torres, além disso, solicitou a colaboração direta de Ihering para classificar os materiais zoológicos que encontrou nos sambaquis do Delta do Paraná (Torres 1911: 259; 289).

Décadas mais tarde, especificamente nos anos 1930, o arqueólogo argentino Antonio Serrano (1899-1982), depois de sua temporada de pesquisas no Sul do Brasil, ${ }^{22}$ retomou as pesquisas de Ihering sobre os sambaquis (Serrano 1938); e, principalmente, reafirmou as conclusões do diretor do Museu Paulista sobre as relações pré-históricas entre os Guaranis e os povos andinos do noroeste argentino (Serrano 1937: 39-42). Que Torres e Serrano tenham dialogado com os trabalhos de Ihering não surpreende. Pois Ihering foi até mesmo tido como especialista em Arqueologia Calchaqui. Em um artigo sobre o tema, o famoso americanista Daniel Brinton ${ }^{23}$ cotejou as pesquisas de Ihering, Ameghino, Ambrosetti, Quevedo e Hermann Ten Kate (Brinton 1899). Ihering é citado por

(21) Torres apresentou uma visão mais sintética de seus trabalhos na região em um artigo publicado em 1907 (Torres 1907).

(22) Antonio Serrano veio ao Brasil como bolsista da Comissão Nacional de Cultura de Buenos Aires, instituição oficial que enviava anualmente dez cientistas argentinos para países estrangeiros (Serrano 1937: 3). A obra de Serrano é analisada por Podgorny (2004).

(23) Nascido nos Estados Unidos, Daniel Brinton (1837-1891) foi professor de Arqueologia e Lingüística na Universidade da Pensilvânia. Sua obra capital - The American Race: A Linguistic Classification and Ethnographic Description of the Native Tribes of North and South America (1891) - é um grande catálogo dos indígenas do continente americano. Este livro tornou-se um manual de consulta em fins do século XIX; um mapa para os que se orientavam pelo intrincado panorama lingüístico e etnográfico da América (Baker 2000).
Brinton em todas as páginas de seu artigo, sendo considerado um dos formuladores dos objetos e problemas da Arqueologia Calchaqui.

As pesquisas arqueológicas de Ihering, em larga medida resultantes de seus diálogos e cooperações com os museus e cientistas argentinos, ilustram bem como as relações internacionais foram cruciais para a formulação de teses sobre a Pré-História sul-americana em fins do século XIX e começo do XX. Ilustram ainda como as pesquisas arqueológicas, ao circularem mundialmente, conformaram-se aos contextos locais e ajudaram a conferir respostas para questões políticas. Assim, se a faceta americanista de Ihering marcou-se pelo diálogo com os argentinos e pela qualidade internacional de seus estudos, lapidou-se também pelo uso da Arqueologia para lastrar uma política colonial.

\section{Agradecimentos}

Este artigo é uma versão modificada e ampliada, em vernáculo, de um texto que ofereci ao simpósio La Arqueología Sudamericana en Perspectiva Histórica: Identidades, Narrativas y Poder, organizado por mim e Javier Nastri (Museu Etnográfico da Universidade de Buenos Aires) para a IV Reunión Internacional de Teoría Arqueológica de América del Sur, realizado, em julho de 2007, na cidade San Fernando del Valle de Catamarca, Argentina. Devo agradecer a Alejandro Haber (Universidade Nacional de Catamarca), por ter me convidado para organizar o simpósio. Agradeço também a Javier Nastri pelo entendimento harmonioso que tivemos durante a organização do simpósio. Francisco Noelli e Pedro Paulo Funari leram a versão inicial deste trabalho. As idéias nele apresentadas são de minha responsabilidade, mas sou muito grato a eles por seus comentários. Agradeço finalmente à Fundação de Amparo à Pesquisa do Estado de São Paulo (FAPESP), que, entre 2000 e 2008, forneceu-me as bolsas sem as quais este e outros trabalhos não poderiam ser escritos. 
FERREIRA, L.M. Dialogues of South American Archaeology: Hermann von Ihering, the Paulista Museum and the Argentine museums at the end of nineteenth century and beginning of twentieth century. Revista do Museu de Arqueologia e Etnologia, São Paulo, 19: 63-78, 2009.

\begin{abstract}
The paper aims at demonstrating that the archaeological views of Hermann von Ihering were the result of his exchanges with Argentinian scholars. As the first director of the Paulista Museum, São Paulo, Brazil, von Ihering, thanks to his interaction with several colleagues, was able to set up colonial policies in Brazil and beyond.
\end{abstract}

Keywords: Paulista Museum - Argentian museums - South America Archaeology - Colonial politics.

\title{
Documentos
}

BROWN GOODE, G.

1894 Carta de G. Brown Goode (Assistant Secretary of Smithsonian Institution), 18 de julho de 1894. Fundo do Museu Paulista (Direção e Administração), Pasta 69.

1896 Carta de Brown Goode para Hermann von Ihering. Washington, 29 de julho de 1896. Fundo do Museu Paulista (Direção e Administração), Pasta 70.

CARTAS DA SMITHSONIAN INSTITUTION

1896a Washington, 28 de julho de 1896. Fundo do Museu Paulista (Direção e Administração), Pasta 70.

1896b Washington, 24 de junho de 1896. Fundo do Museu Paulista (Direção e Administração). Pasta 70.

IHERING, H. VON

1894a Ofício de Hermann von Ihering ao IHGB, 21 de setembro de 1894. Fundo do Museu Paulista (Direção e Administração), Pasta 69.
1897 Ofício de Hermann von Ihering ao Secretário do Interior, 12 de julho de 1897. Fundo do Museu Paulista (Direção e Administração), Pasta 71.

1909a Ofício para o Secretário do Interior, 23/ 09/1909. Fundo do Museu Paulista (Direção e Administração), Pasta 89.

1909b Ofício para as Secretarias do Interior, Agricultura, Fazenda e Justiça e para o Presidente do Estado, 2/12/1909. Fundo do Museu Paulista (Direção e Administração), Pasta 89.

1914 Inventário e Descrição do Acervo Arqueológico, Etnográfico e Histórico. Fundo do Museu Paulista, L211 e L212.

LANGLEY, S.P.

1897 Carta de S. P. Langley, secretário da Smithsonian Institution. Washington, 13 de abril de 1897. Fundo do Museu Paulista (Direção e Administração), Pasta 71.

\section{Referências bibliográficas}

ADAM, L.

1900 Le Parler des Caingangs. Congrés International des Américanistes, XII Session tenue a Paris. Paris: Kraus: 317-331.

AMBROSETTI, J.B.

1894a Los Indios Cainguá del Alto Paraná (Misiones). Boletin del Instituto Geográfico Argentino, 15: 661-744. 1894b Los Paraderos precolombianos de Goya (Provincia de Corrientes). Boletin del Instituto Geográfico Argentino, 15: 401-422.

1895 Las Grutas Pintadas y los Petroglyfos de la Provincia de Salta, con figuras y lámina coloreada. Boletin del Instituto Geográfico Argentino, 16: 311-342. 
Diálogos da arqueologia sul-americana: Hermann von Ihering, o Museu Paulista e os museus argentinos no final do século XIX e início do XX.

Revista do Museu de Arqueologia e Etnologia, São Paulo, 19: 63-78, 2009.

ALVES, A.M. DE A.

2001 O Ipiranga Apropriado: Ciência, Política e Poder: O Museu Paulista (1839-1922). São Paulo: Humanitas.

AMEGHINO, F.

1918 [1880] La Antigüedad del Hombre en el Plata. Buenos Aires: La Cultura Argentina.

AZEVEDO, M. VON IHERING DE

2000 Hermann von Ihering. Boletim CEO Centro de Estudos Ornitológicos, 14: 58-66.

BAKER, L.D.

2000 Daniel G. Brinton's Success on the Road to Obscurity. Cultural Anthropology, 15 (3): 394-423.

BERTONI, G.T.

1924 El Indio Guayaki: Una Raza Interesante y Mal Conocida. Anais do XX Congresso Internacional de Americanistas. Rio de Janeiro, Imprensa Nacional: 103-110.

BOMAN, E.

1905 Migrations Précolumbiennes dans le Nord-Ouest de l'Argentine. Journal de la Societé des Americanistes de Paris, 2 (2): 91-108.

BRINTON, D.

1891 The American Race: A Linguistic Classification and Ethnographic Description of the Native Tribes of North and South America. New York: N. C. C. Hodges.

1899 The Calchaqui: an Archaeological Problem. American Anthropologist, 1 (1): 41 44.

BSUMEK, E.M.

2004 The Navajos as Borrowers: Stewart Culin and the Genesis of the Ethnographic Theory. New Mexico Historical Review, 79 (3): 319-351.

CHAMBERLAIN, A.F.

1906 South American Linguistic Stocks. Congrés International des Américanistes, Quinziéne Session. Québec, Kraus: 187-204

1912 The Allentiacan, Bororoan and Calchaquian Linguistic Stocks of South America. American Anthropologist, 14 (3): 499-507.

$\mathrm{COHN}, \mathrm{B}$.

1996 Colonialism and Its Forms of Knowledge: the British in India. Princeton: Princeton University Press.

DANIEL, G.

1950 A Hundred Years of Archaeology. London: Duckworth.

DÍAZ-ANDREU, $\mathrm{M}$.

2007 Internationalism in the Invisible College: Political Ideologies and Friendships in
Archaeology. Journal of Social Archaeology, 7 (1): 29-48.

FERREIRA, L.M.

1999 Vestígios de Civilização: O Instituto Histórico e Geográfico Brasileiro e a Construção da Arqueologia Imperial (1838-1870). Revista de História Regional, 4 (1): 9-36.

2003 História Petrificada: A Arqueologia Nobiliárquica e o Império Brasileiro. Cadernos do CEOM, 17 (18): 11-40.

2005a Arqueologia do Sul do Brasil e Política Colonial em Hermann von Ihering. Anos 90, 12 (21): 415-436.

2005b Footsteps of American Race: Archaeology, Ethnography and Romanticism in Imperial Brazil. In: Funari, P.P.A.; Zarankin, A.; Stovel, E. (Eds.) Global Archaeology Theory: Contextual Voices and Contemporary Thoughts. New York, Kluwer Academic: 337-352.

2007 Território Primitivo: A Institucionalização da Arqueologia no Brasil (1870-1917). Campinas: Unicamp/Instituto de Filosofia e Ciências Humanas (Tese de Doutorado).

FIGUEIRÔA, S.F.M. DE

1998 Mundialização da Ciência e Respostas Locais: sobre a institucionalização das ciências naturais no Brasil (de fins do século XVIII à transição do século XX). Asclépio, 50 (2): 107-123.

FROST, F.J.

1993 Voyagers of the Imagination. Archaeology, 46 (2): 44-51.

FUNARI, P.P.A.

1994 Arqueologia Brasileira: visão geral e reavaliação. Revista de História da Arte e Arqueologia, 1: 23-41.

1998 Destruction and Conservation of Cultural Property in Brazil: Academic and Practical Challenges. In: Teoria Arqueológica na América do Sul. Campinas: Primeira Versão, 76: 33-51.

1999 Brazilian Archaeology: A Reappraisal. In: Politis, G.; Alberti, B. (Eds.) Archaeology in Latin American. London, Routledge: 17-37.

GAGLIARDI, J.M.

1989 O Indígena e a República. São Paulo: Hucitec/EDUSP/Secretaria de Estado da Cultura de São Paulo.

GENTILE, M.E.

2001 Etnohistoria de una Creencia Andina en el Noroeste Argentino. Bull. Inst. Fr. Études Andines, 30 (1): 2-76. 
GOLDIE, T.

1995 The Representation of the Indigene. In: Aschroft, B.; Griffiths, G.; Tiffin, H. (Eds.) The Post-Colonial Studies Reader. London, Routledge: 232-237.

GOLDSTEIN, D.

1994 "Yours for Science": The Smithsonian Institution's Correspondents and the Shape of Scientific Community Nineteenth-Century America. Isis, 85 (4): 573-599.

GOSDEN, C.

1999 Anthropology and Archaeology: A Changing Relationship. London: Routledge.

GUERRINO, A.A.

1984 La Medicina en La Conquista del Desierto. Buenos Aires: Circulo Militar.

GUTIERREZ, J.M.

1875 Bibliografía: Los Caballos Fósiles de la Pampa Argentina descriptos por el Dr. D. German Burmeister, director del Museo Público de Buenos Aires. Obra ejecutada por órden del Superior Gobierno de la Província de Buenos Aires para ser presentada en la Exposicion de Filadelfia. Con VIII láminas litografiadas. Buenos Aires, imprenta de la Tribuna, 1875. Revista del Rio de La Plata, 9: 664-672.

1877 Los Estudios Actuales sobre el Hombre Prehistórico en la República Argentina. Revista del Rio de La Plata, 13: 651-657.

HABER, A.

1994 Supuestos Teórico-Metodológicos de la Etapa Formativa de la Arqueología de Catamarca (1875-1900). Publicaciones Arqueología, 47: 31-54.

HARRIS, M.

1968 The Rise of Anthropological Theory: a History of Theories of Culture. New York: Crowell.

1993 Introducción a la Antropología General. Madrid: Alianza Universidad Textos.

HASEMAN, J.D.

1912 Some Notes on the Pawumwa Indians of South America. American Anthropologist, 14 (2): 333-349.

HEGER, F.

1924 Muyrakitãs. Anais do XX Congresso Internacional de Americanistas. Rio de Janeiro, Imprensa Nacional: 255-260.

HINSLEY, C.M.

1981 The Smithsonian Institution and the American Indian: Making Anthropology in Victorian America. Washington: Smithsonian Institution Press.
HOCQUENGHEM, A.M.

2004 Una Edad del Bronce en los Andes Centrales: Contribución a la Elaboración de una Historia Ambiental. Bull. Inst. Fr. Études Andines, 33 (2): 271-329.

HRDLICKA, A.

1917 The Genesis of the American Indians. Proceedings of the Second Pan American Scientific Congress. Section I, Anthropology. Washington: Government Printing Office.

IHERING, H. VON.

1895a A Civilização Pré-Histórica no Brasil Meridional. Revista do Museu Paulista, 1: 33-159.

1895b Conchas Marinhas na Formação Pampeana de La Plata. Revista do Museu Paulista, 1: 223-232.

1897a Bibliografia. Revista do Museu Paulista, 2: 466-477.

1897b Os Moluscos dos Terrenos Terciários da Patagônia. Revista do Museu Paulista, 2: 73-114.

1900 Bibliografia. Revista do Museu Paulista, 4: 565-567.

1902a On the Molluscan Fauna of the Patagonian Tertiary. Proceedings of the American Philosophical Society, 41 (169): 132-137.

1902b Historia de las Ostras Argentinas. Anales del Museo Nacional de Buenos Aires, 7: 109-123.

1903a El Hombre Prehistórico del Brasil. Buenos Aires: Historia, 1: 161-169.

1903b A Origem dos Sambaquis. RIHGSP, 8: 446-457.

1904a Über das Natürliche Vorkommen von Nephrit in Brasilien. Internationaler Amerikanisten-Kongress. Vierzehnte Tagung, XIV, Stuttgart: 507-515.

1904b O Museu Paulista em 1901 e 1902. Revista do Museu Paulista, 6: 1-22.

1904c Arqueologia Comparativa do Brasil. Revista do Museu Paulista, 6: 519-580.

1904d Os Guaianáses e Kaingangs do Estado de São Paulo. Revista do Museu Paulista, 6: 23-44.

1906 A Etnologia do Brasil Meridional. RIHGSP, 11: 220-236.

1907a A Antropologia do Estado de São Paulo. Revista do Museu Paulista, 7: 202-257.

1907b As Cabeças Mumificadas pelos Índios Mundurucus. Revista do Museu Paulista, 7: 179-201.

1910 A Etnografia do Brasil Meridional. Actas del Congreso Internacional de Americnistas. Buenos Aires: 250-264.

1911a Os Botocudos do Rio Doce. Revista do Museu Paulista, 8: 33-51. 
Diálogos da arqueologia sul-americana: Hermann von Ihering, o Museu Paulista e os museus argentinos no final do século XIX e início do XX.

Revista do Museu de Arqueologia e Etnologia, São Paulo, 19: 63-78, 2009.

1911b A Questão dos Índios do Brasil. Revista do Museu Paulista, 8: 112-140.

1911c Bibliografia. Revista do Museu Paulista, 8: $512-525$.

1969 [1885]A Lagoa dos Patos. Organon, 14: 101-142.

IHERING, H; IHERING, R. VON.

1911 O Museu Paulista $\mathrm{n}^{\text {os }}$ anos de 1906 a 1909. Revista do Museu Paulista, 8: 1-22.

IHERING, R. VON.

1914 O Museu Paulista ${ }^{\text {os }}$ anos de 1910, 1911 e 1912. Revista do Museu Paulista, 9: 5-24.

JOHNSON, J.S.

1993 Conservation and Archaeology in Great Britain and the United States: a Camparison. Journal of the American Institute for Conservation, 32 (3): 249-269.

KAESER, M.A.

2000 Nationalisme et Archéologie: quelle histoire? Revue d'Histoire des Sciences Humaines, 2: 155-162.

2001 L'internationalisation de la Préhistoire, une manouevre tactique? Les conséquences épistémologiques de la fondation des congrés internationaux d'anthropologie et d'archéologie préhistoriques. In: Blanckaert, C. (Ed.) Les Politiques de l'antropologie: Discours et Práctiques en France (1860-1940) (Histoire des Sciences Humaines). Paris: L'Harmattan: 201-230.

2002 On the International Roots of Prehistory. Antiquity (Special Section: Ancestral Archives, Explorations in the History of Archaeology), 76: 170-177.

KATE, H.F.C. TEN.

1893 Rapport Sommaire sur une Excursion Archéologique dans les Provinces de Catamarca, de Tucuman et de Salta. Revista del Museo de La Plata, 5: 331-348.

KOHLSTEDT, S.G.

1988 History in a Natural History Museum: George Brown Goode and the Smithsonian Institution. The Public Historian, 10: 2, 7-26.

LAFUENTE, A; ORTEGA, M.L.

1992 Modelos de Mundilización de la Ciencia. Madrid: Arbor, Tomo CXLII: 93-117.

LAFUENTE, A.

2000 Enlightenment in an Imperial Context: Local Science in the Late EighteenthCentury Histpanic World. Osiris, 15 (2): 155-173.

LEWIN, R.

1997 The Bones of Contention: controversies in the search for human origen. Chicago: Chicago University Press.
LIMA, A.C. DE S.

1995 Um Grande Cerco de Paz: Poder Tutelar, Indianidade e Formação do Estado no Brasil. Petrópolis: Vozes.

LIMA JÚNIOR, J.B.

1906 Relatório da Exploração dos Rios Feio e Aguapeí. São Paulo: Comissão Geográfica e Geológica de São Paulo.

LOOMBA, A.

2000 Colonialism/Postcolonialism. London: Routledge.

LOPES, M.M; PODGORNY, I.

2001 The Shaping of Latin American Museum of Natural History (1850-1990). In: Macleod, R. (Ed.) Nature and Empire: Science and the Colonial Enterprise. Chicago: Chicago University Press: 108-118.

2007 Oceanos e Continentes em Debate. Revista de História e Estudos Culturais, 4 (3): 2-19.

LOPES, M.M.

2001 Viajando pelo Campo e pelas Coleções: Aspectos de uma Controvérsia Paleontológica. História, Ciências, Saúde Manguinhos, 8, Suplemento: 881-897.

MACGUIRE, R.H.

1992 A Marxist Archaeology. San Diego: Academic Press.

MORENO, F.P.

1901 Notes on Anthropogeography of Argentina. The Geographical Journal, 18 (6): 574-589.

NIMUENDAJU, C.

1982 [1912] Textos Indigenistas. São Paulo: Editora Loyola.

ORTMANN, A.E.

1910 Terciary Archhelenis. The American Naturalist, 44 (520): 237-242.

PACZENSKY, G. VON.

1985 Nefertiti quiere volver a casa: los tesoros del Tercero Mundo en los Museos de Europa. Madrid: Planeta.

PETERSEN, K.H; RUTHERFORD, A.

1995 Fossil and Psyche. In: Aschcroftt, B.; Griffiths, G.; Tiffin, H. (Eds.) The PostColonial Studies Reader. London, Routledge: 185-189.

PETRIE, F.

1904 Methods and Aims in Archaeology. London: MacMillan.

PODGORNY, I.

1997 A quién entregar las reliquias nacionales? La organización del Museo de La Plata, Argentina, entre 1880 y 1916. In: Mora, G.; Díaz-Andreu, M. (Orgs.) La Cristalización del 
Pasado: Génesis y Desarrollo del marco institucional de la Arqueología en España. Madrid/Málaga, Ministerio de Cultura/ Universidad de Málaga: 747-754.

2000 Una Exhibición Científica de la Pampa (Apuntes para una Historia de la Formación de las Colecciones del Museo de La Plata). Revista de História da Arte e Arqueologia, 4: 55-73.

2004 “Tocar para Creer”: La Arqueología en la Argentina (1910-1940). Anales del Museo de América, 12: 147-182.

PODGORNY, I; POLITIS, G.

1992 Qué Sucedió a la Historia? Los esqueletos araucanos del Museo de La Plata y la Conquista del Desierto. Arqueología Contemporánea, 3: 73-79.

POLANCO, X.

1990 Une Science-monde: la mondialisation de la science européenne et la création de traditions scientifiques locales. In: Polanco, X. (Ed.) Naissance et Développement de la Science-Monde: production and reproduction des communautés scientifiques en Europe et en Amérique Latine. Paris, Ed. La Découverte/Conseil de l'Europe/ UNESCO: 5-15.

POLITIS, G.

1995 The socio-politics of the Development of Archaeology in Hispanic South America. In: Ucko, P.J. (Ed.) Theory in Archaeology: a world perspective. London, Routledge: 197-235.

\section{REVIEWED WORKS}

1908 Archhelenis und Archinotis: Gesammelte Beiträge zur Geschichte der Neotropischen Region by Hermann von Ihering. The Geographical Journal, 32 (2): 169-170.

1909 Archhelenis und Archinotis: Gesammelte Beiträge zur Geschichte der Neotropischen Region by Hermann von Ihering. Bulletin of the American Geographical Society, 41 (5): 290-291.

RUEDA, C.H.L.

2003 Arqueología Colombiana: Ciencia, Pasado y Exclusión. Bogotá: Colciencias.

SALDAÑA, J.J.

1986 Marcos Conceptuales de la Historia de las ciencias en Latinoamérica: Positivismo e Economicismo. Quipu, 1: 57-79.

1993 Nuevas tendencias en la Historia de la ciencia en América Latina. Cuadernos Americanos, 38 (2): 69-91.

1999 Western and no-western science: history and perspectives. In: World Conference on Science. ICSU-UNESCO, Budapest, 19 pp.

2000 Ciência e Identidade Cultural: História da Ciência na América Latina. In: Figueirôa, S.F. de M. (Org.) Um Olhar sobre o Passado: História das Ciências na América Latina. Campinas, Editora da Unicamp: 11-31.

SÁNCHEZ, R.N.

2004 El Pasado con Intención: Hacía una reconstrucción del pensamiento arqueológico en Venezuela. Caracas: Facultad de Ciencias Económicas y Sociales/Fondo Editorial Tropykos.

SAVILLE, M.H.

1913 Precolumbian Decoration of the Teeth in Ecuador. With some Account of the Ocurrence of the Custom in other parts of North and South America. American Anthropologist, 15 (3): 377-394.

SCHÁVELZON, D.

2004 The South America Connection: Gaston Maspero, Egyptology and Americanist Archaeology at Montevideo, 1868. Bulletin of the History of Archaeology, 14 (1): 15-24.

SCHMIDT, W.

1942 Etnologia sul americana. Círculos culturais e estratos culturais na América do Sul. São Paulo: Companhia Editora Nacional.

\section{SCHWARCZ, L.M.}

1989 O Nascimento dos Museus Brasileiros (1870-1910). In: Miceli, S. (Org.) História das Ciências Sociais no Brasil. Vol I. São Paulo, Ideps: 20-71.

SERRANO, A.

1937 Subsídios para a Arqueologia Brasileira do Brasil Meridional. São Paulo: Revista do Arquivo Municipal, 36: 3-42.

1938 Los Sambaquis o Concheros Brasileños. Revista del Instituto de Antropología de la Universidad de Tucumán, 3 (1): 44-89.

STAGNARO, A.A.

1993 La Antropología en la Comunidad Científica: entre la origen del hombre y la caza cráneos-trofeo (1870-1910). Alteridades, 6 (3): 53-65.

TERRERA, G.A.

1974 Caciques y Capitanejos en la Historia Argentina: la epopeya del desierto. Buenos Aires: Plus Ultra.

TORRES, L.M.

1907 Arqueología de La Cuenca del Río Paraná. Revista del Museo de La Plata, 14: 53-122. 
Diálogos da arqueologia sul-americana: Hermann von Ihering, o Museu Paulista e os museus argentinos no final do século XIX e início do XX.

Revista do Museu de Arqueologia e Etnologia, São Paulo, 19: 63-78, 2009.

1911 Los Primitivos Habitantes del Delta del Paraná. Buenos Aires: Imprenta de Coni Hermanos.

TRIGGER, B.G.

1990 A History of Archaeological Thought. Cambridge: Cambridge University Press. VESSURI, H.

1986 Los Papeles Culturales de la Ciencia en los países subdesarrollados. In: Saldaña, J.J. (Ed.) El Perfil de la Ciencia en América. Cuadernos de Quipu, 1: 7-17.

\section{VIRCHOW, R.}

1888a Sur la Provéniance de la néphrite et de la jadeite. Congrés International des Américanistes. Berlim: Compte-Rendu de la Septiéme Session: 207-216

1888b La Craniologie Américaine. Congrés International des Américanistes. Berlim: Compte-Rendu de la Septiéme Session: 251-260.

YOUNG, R.

2001 Postcolonialism: An Historical Introduction. Oxford: Blackwell Publishing.

Recebido para publicação em 22 de maio de 2009. 